\title{
Editorial
}

\section{The I980 Reith Lectures}

The claim that the scope of medical ethics properly embraces society at large and must not be the concern solely of doctors provided the leitmotif of lawyer Ian Kennedy's I980 BBC Reith Lectures. We shall be publishing later in the year more detailed analysis of these as well as Kennedy's response to criticisms of the series (one of the concomitants of quarterly publication is that discussion of hitherto topical issues necessarily tends to be sub specie aeternitas!). Meanwhile suffice to say that Kennedy succeeded in bringing together many of the familiar moral problems arising from medical practice and creating around them a wide public interest and debate. In particular he emphasised the need to recognise the considerable morally evaluative content of many medical decisions, and the consequent need to distinguish within such decisions technical expertise and moral evaluation. The latter was properly 'not the preserve of any one group ... but part of the general moral and ethical order by which we live.'

Among his specific examples Kennedy discussed truth telling and lying in medical practice, criteria for resuscitation in various circumstances, management of malformed new born babies, and abortion. He demonstrated that all these involved complex ethical issues and stated that they deserved rigorous ethical analysis, none of which he pretended to offer. Rather he urged that the complexity should be recognised, that the analysis be shared with the public at large, and that steps be taken to ensure that doctors were better trained in such ethical analysis themselves.

He attacked what he saw as excessive concern with science and technology in modern medicine and the disproportionate allocation of resources to hospital medicine, not only in the developed but also in the developing world. He linked this to a perceived medical tendency to reify diseases and then to separate people from their diseases in order to concentrate on the latter while forgetting about the former. He deprecated the common medical assumption that there was always something to be done, and the emphasis of medicine on curing, at the expense of prevention of illness and accidents and the promotion of health. He specified the 'major destroyers of our day' as cigarettes, alcohol, poor diet and accidents and urged greater effort to combat these. He lamented the inequality of distribution of health care, heavily weighted as it is, even in the developed countries, against the poor. He cited the findings of President of the Royal College of Physicians Sir Douglas Black's report Inequalities in Health and suggested that its official rejection was evidence of how 'the extent of the re-examination and re-orientation of values called for is breathtaking.'

In his analysis of the role of the medical profession he claimed that it had too much power to make political and moral decisions. Moreover the doctor functioned too much as a 'socialising agent', whether by prescribing Valium, 'even if this means that the social and economic conditions which give rise to the unhappiness remain unaddressed', or by helping the forces of law 'in a society under stress' to become more vigilant and oppressive 'by classing political difference as deviance, social protest as irrational and dangerous, sexual predilection as sick depravity'.

In their personal relations with patients he saw doctors as infantilising them and undermining their autonomy and powers of self determination by paternalism. To counter this Kennedy advocates more 'consumerism', with greater emphasis on the requirements of informed consent. He also suggests ('for the future') that 'a new method of supervision and sanction must be created with power of suspension or removal from practice of those found to be incompetent'.

There are several aspects of Kennedy's analysis, among them and fundamentally his accounts of the concepts of disease, illness and health and their mental counterparts, which may eirenically be called 'debatable'. So too may his assertions about the proper social functions of doctors - indeed he seems to attack them for both being agents of social control - when they prescribe Valium or make certain sorts of psychiatric diagnoses - and for not being agents of social control - when they practise personal medicine rather than influencing governments (as apparently Schweitzer should have done) to change along the lines he advocates. He seems to forget that people like doing different things with their lives and that treating the sick is a very different sort of activity, and involves a different social role, from putting pressure on governments. It is almost as though he assumes that the sole purpose of those who practise medicine is to 
maximise happiness, and that they should thus behave only in those ways which achieve this end most effectively. The inadequacy of such hedonistic utilitarianism hardly needs stating and is in any case pointed up by another strand in Kennedy's argument, notably his advocacy of patients' autonomy and self-determination; if these are rights of patients then they are also rights of doctors and other health professionals.

Kennedy's lectures have stirred up a certain ill will among the British medical profession - more than their content alone could reasonably account for. Most probably it is their combatative style and phraseology, designed no doubt to achieve the publicity which was in fact achieved, that is responsible. Thus he exhorts his listeners to 'become the masters of medicine not its servants' (hardly a relationship of autonomous equals, that!) and to 'take over'; with regard to hospital consultants he recalls Bevan's famously hostile claim that 'he choked their mouths with gold'; psychiatrists have 'bootstrapped themselves into intellectual respectability' but, he suggests, talk 'psychobabble'; medical schools 'must simply be dragged back into our world and out of their hermetically sealed cocoon in which we are the counters with which the game of life is played'. In the quest for reform 'the profession is not going to help'; it has 'an unyielding policy of hostility', participates in 'chauvinist and lofty ignorance' and manifests 'overweening hubris'.

All this aggro makes good copy for the popular media but it does not encourage doctors to cooperate in the thoughtful exercises which Kennedy is properly advocating - rather it tends to make them switch off their radios and their $n$ inds against 'just another bit of doctor-bashing'. Whether the advantage of popular publicity for his views outweighs this very great disadvantage remains doubtful.

\section{Huntington's chorea}

In this issue we publish a discussion concerning ethical aspects of the inherited disease, Huntington's chorea, in which the author considers some problems associated with new medical approaches to this inexorable degenerative disease of the central nervous system. Dr Brackenridge writes: 'it would be irresponsible to embark on them without considering some likely [ethical and practical] implications'.

The paper represents an underinvestigated area in medical ethics and responses to Brackenridge's initial remarks would be valuable, whether as articles or letters for publication in the fournal, or simply as private correspcndence. One necessary addition to Brackenridge's discussion which immediately comes to mind is an explicit ac- knowledgment of the presumably crucial role of $\frac{\mathbb{D}}{2}$ potential victims and actual patients (those whom remain capable) in helping to make the required moral evaluations. Dilemmas such as whether, with? a family history of Huntington's chorea, it is $\vec{F}$ preferable to discover one's diagnosis even at the? cost of temporarily inducing premature symptoms $\frac{0}{0}$ of the disease, and dilemmas concerning the quality $\overline{\bar{c}}$ versus the quantity of life offered by different ${ }_{\bar{\sigma}}^{-}$ procedures, these surely require the views of the people most closely concerned.

\section{New editor, old policy}

There are those who will hope that with the appointment of a new editor this journal will take a. new direction-more 'positive' in its orientation, $\vec{\omega}$ more conscious of a need to 'guide' doctors ando other health professionals along the paths of righteousness, less tolerant of the uncertainty and $\vec{z}$ variability which characterise so much contemporary thought about medical ethics and indeed ethics in $)$ general. They will be disappointed. The fournal $\overrightarrow{0}$ was established 'to provide a forum for the reasoned discussion of moral issues arising from the provision. of medical care' and from a standpoint independento of any particular professional, political, religious or philosophical moral stance. This policy, enunciated $\bar{O}$ by the retiring editor in his first editorial, has been successfully maintained over the last six years and 0 it will continue to be the fournal's raison d'être.

The policy should not, however, be confused with 3 the view that 'anything goes', for its requirement of 'reasoned discussion' is a rigorous one, and excludes? much that has been and continues to be written $\overline{3}$ about medical ethics. Furthermore, and only ap- $-\Phi$ parently paradoxically, independence of particular $\frac{}{3}$ professional, political, religous or philosophical viewpoints entails a transdisciplinary embrace of $\frac{\varrho}{\beta}$ any reasoned viewpoint, regardless of its provenance. Thus health professionals who believe that only their 5 peers are qualified to discuss the often complex $\frac{D}{0}$ moral problems of medical practice will continue to be disappointed in this journal's desire to open such $N$ discussion to as broad a range of contributors and readers as it may.

Reasoned discussion between people of various $\omega$ disciplines carries another important implication and ${ }^{2}$ that is their need to use a common language. Mere ${ }^{\circ}$ adherence to English is, alas, no longer sufficient to achieve such intellectual commerce; the professional $\stackrel{?}{+}$ jargons of, for example, medicine, sociology, $\frac{T}{0}$ philosophy, law and religion, are all expressible in $\frac{\vec{\Phi}}{\Phi}$ our technically single language, yet they have $\frac{\rho}{\square}$ become often incomprehensible to all except $\stackrel{\mathbb{Q}}{\square}$ specialists. Our aim, it is worth reiterating, is to publish papers 'in jargon-free English . . . clearly 8 written so as to be accessible to any intelligent reader'. 